\title{
The Effect of Cooperation-Strategy Fit on the Performance of Subcontractors-Focused on Samsung Electronics' Subcontractors
}

\author{
Min-Jae Kim, Jeongki Lee, and Jun-Young Park
}

\begin{abstract}
This study examines the effects of the relationships between cooperative relationships and competitive strategies in domestic companies, as well as of such cooperation-competitive strategic fit, on subcontractors. Toward this end, 90 primary subcontractors of Samsung Electronics were examined based on hypotheses. The findings of this study revealed that primary subcontractors of Samsung Electronics, similarly to the predict-tion of the contingency theory, adopted competitive strategies fit for their cooperative relationships. Also, compared with low-performance groups, high-performance groups had higher levels of cooperative relationship-competitive strategy fit. These findings imply that the cooperative relationship-competitive strategy fit has positive effects on corporate performance. Thus it is argued that for subcontractors, their cooperation with their principal contractor companies have important effects on their competitive strategy and on their business performance.
\end{abstract}

Index Terms - Strategy fit, competitive strategy, intensity of cooperation, and quality of cooperation

\section{INTRODUCTION}

South Korea's economy achieved industrialization in so-called compressed growth, led by large companies, but polarity between large companies and SMEs (small and medium-sized enterprises) deepened [1]. For instance, the profitability of large companies increased from $5.56 \%$ in 2009 to $6.80 \%$ in 2010, while that of SMEs decreased from $4.84 \%$ in 2009 to $4.47 \%$ in 2010 [2]. This phenomenon raised diverse issues concerning SMEs' competitiveness.

Regarding SMEs' competitiveness, the environment-competitive strategy fit has been emphasized [3]-[5]. Studies conducted in South Korea presented contingency theories that appropriate business strategies should be implemented according to the uncertainty of the business climate [6].

Together with this, in recent years, studies have been conducted to emphasize the importance of SMEs' cooperation with large companies [1], [7], [8]. These studies argue that the cooperation between large companies and SMEs not only boosts the parent companies' business performance but also enhances SMEs' competitiveness through cooperation, thus

enhancing the health of the entire business ecology. However, most studies have thus far focused on the relationships between cooperation and corporate performance [9]-[11], and these studies did not present detailed measures to boost the

Manuscript received November 9, 2013; revised January 5, 2014.

The authors are with Kyungpook National University, Daehak-ro, buk-gu, Daegu, South of Korea (e-mail: ahsimsim@naver.com, knu06@knu.ac.kr, junyounggs@naver.com). effect of cooperation.

This study examined cooperative relationships, and relationships between competitive strategies. Existing studies conducted from the perspective of contingency theories mostly examined the relationships between the environment and competitive strategies, and between internal corporate capabilities [12]-[14]. However, in the case of SMEs, their cooperation with large companies is important, and thus it is considered the most important to examine the relationships between cooperative relationships and competitive strategies. Also, this study took diverse-dimensional approaches to cooperative relationships, considering cooperative relationships in terms of intensity of cooperation from the behavioral viewpoint, and quality of cooperation from the viewpoint of attitude.

This study thus derives detailed cooperative measures for shared growth, and identifies the effect of such cooperative relationships on SMEs' competitiveness and performance, thus offering practical implications.

\section{THEORETICAL BACKGROUND}

\section{A. Strategic Fit}

Fit started with the contingency theory which is dealt with in research on strategy and organizational theories [15]. Contingency theory is used as diverse meanings depending on the theme of research, but organizational performance is generally seen as the result of fit or match between two or more factors of organizational environment, strategy, structure, system, style and culture [16]. The strategic contingency theory proposed by [17] is that corporate strategies should be fit to the corporation's situation to accomplish greater achievements [13], [18]-[20]. In other words, since the environment in which an organization is influences organizational strategies, the organization should fit its strategies to the environment to accomplish greater achievements [13], [21], [22], based on the relation between the environment and strategies, measured the level of fit, types of fit strategies will change depending on the environmental uncertainty. Also, afterward, many studies reported that if the strategic fit between corporate environmental characteristics and strategies is greater, the corporate performance will be greater [18], [23].

Theories from the resource-based viewpoint saw that corporate resources and capabilities are heterogeneous, and that corporations should select necessary strategies according to their resources and capabilities [24], [25]. Researchers of resource-based viewpoint emphasized that corporate 
performance can be created by binding intangible resourcesthat have greater specificity, and that are difficult to transfer and imitate [24], [26]. Scholars of resource-based viewpoint saw that to acquire resources such as capital, technology, knowhow and information, cooperation with external parties is needed [28]. Particularly, SMEs in South Korea, which are very poor, have much difficulty accumulating resources on their own, and thus to overcome such difficulty, their cooperation with large companies is deemed to be important.

In the case of domestic SMEs, the fit of relationships between SMEs' cooperative relations with large companies and competitive strategies is considered more important than the fit between strategies, internal corporate factors, and the environment.

\section{B. Competitive Strategies, and Cooperative Relationships with Large Companies}

Cooperation is defined to mean the process by which two or more independent firms pursue common goals in expectation of mutual interests [29], [30] or the process by which individuals or organizations form psychological relationships to earn interests amid interaction [31], [32].

The activity of cooperation between firms includes two processes, namely, formation of relationship and performance of activity [33]. In the relation formation stage, the quality of relationship factor, meaning the evaluation at attitude level, is important. In the activity performance stage, the intensity of relationship, meaning the evaluation at the behavioral level, is important. As such, two variables are variables of evaluating different levels of relationship [34], but previous studies on cooperation mix and use two concepts [35].

Behavior variable, intensity of relationship, shows the behavioral concept intended to maintain the relationship with current cooperation weight [34]. On the other hand, attitude variable, the quality of relationship, is the variable that can best predict the relationship between level of satisfaction and the future [36]. Thus, this study examines cooperative relationship in terms of behavioral level and attitude level.

The intensity of relationship means the intimacy of relationship from the viewpoint of social networks. In other words, it is expressed in terms of the frequency of relationships with others, and the frequency of interaction [37]. The greater intensity of relationship means the higher frequency of cooperative relationship, and this means that the frequency of contacts or the time of contacts increases, and that the exchanged resources and information increase. According to previous studies on relationships, the effect of strong relationships improves mutual trust. Thus, important information that cannot be easily acquired is shared. Also, values and cultures are shared between partners, communications are promoted, mutual learning is facilitated, cost of trading is reduced, and investment for future interests is promoted [38], [39]. Thus, cooperation should not be understood as a fixed relationship, but as a continuous thing according to the intensity of relationship [40]. The comprehensive intensity of diverse cooperative activities needs to be identified.

Thus, this study defined the intensity of technical cooperation with the principal company, financial cooperation, sale cooperation and other cooperative activities, as the intensity of cooperation.

The quality of relationship is defined as the degree of mutual relationship [36] or as the evaluated value of overall relationships, meaning the maturity of relationship [41]. Also, according to [42], it is defined as the determination to accept short-term sacrifice in order to put the current revenues and costs first, and to continuously maintain and develop stable relationships. Such quality of relationship means the continuity of not only short-term mutual relationship but also long-term relationship through the relational exchange of two organizations, thus playing a mediating role between relationship and relationship determinants [43].

This study defined the quality of cooperation, based on such concept of relationship, as the evaluation of cooperation satisfaction and the long-term continuity of relationship.

\section{HYPOTHESIS AND RESEARCH MODEL}

\section{A. Hypothesis}

SMEs, compared with large companies, lack finance, manpower, and marketing capabilities, and thus for them, it is important to form and maintain cooperative relationships with large companies. Also, if SMEs weaken their competitiveness, it will make large companies depend on overseas markets for the procurement of parts and materials, which will in turn threatens large companies' competitiveness and sustainability.

Previous studies on cooperation between large companies and SMEs reported that cooperation between firms has positive effects on subcontractors' key capabilities and competitive superiority [33], [44]-[46] argued that cooperative activities provide the method for acquiring information on new products or for more easily developing market-innovative products. Also, [47] argued that a company's knowledge system linkage with other organizations has important effects on its capabilities of developing innovative products. [45] argued that such cooperation improves the possibility of accessing new technology and markets through partnerships, and the capability of providing diverse scopes of products and services.

In addition, according to [48], it is important for SMEs in South Korea to acquire resources from external sources to boost their structurally weakened resource capabilities.

This study, based on such previous studies, established the following hypotheses.

Hypothesis 1. The intensity of cooperation with the principal company and the subcontractors' competitive strategy will have a positive relationship.

Hypothesis 1-1. The intensity of cooperation with the principal company and the subcontractors' marketing differentiated strategies will have a positive relationship.

Hypothesis 1-2. The intensity of cooperation with the principal company and the subcontractors' innovation differentiate strategies will have a positive relationship.

Hypothesis 1-3. The intensity of cooperation with the principal company and the subcontractors' cost superiority strategies will have a positive relationship. 
Notably, if the relationship with the principal company is maintained in the long-term and cooperative form rather than in the traditional check and balance framework, it will have a positive effect on boosting subcontractor SMEs's competitiveness [11], [49].

Thus, this study, like the aforementioned previous studies, saw that the quality of cooperation is important with regard to the effect of cooperative relationships on subcontractors' competitive strategy, and derived the following hypotheses concerning the quality of cooperation and competitive strategy.

Hypothesis 2: The quality of cooperation with the principal company and subcontractors' competitive strategy will have a positive relationship. .

Hypothesis 2-1: The quality of cooperation with the principal company and subcontractors' marketing differentiation strategy will have a positive relationship. .

Hypothesis 2-2: The quality of cooperation with the principal company and subcontractors' innovation differentiation strategy will have a positive relationship.

Hypothesis 2-3: The quality of cooperation with the principal company and subcontractors' cost superiority strategy will have a positive relationship.

Hypotheses 1 and 2 above discussed are based on the normative logic concerning the cooperative relationship and strategic strategy fit and mutual complementation, and the fit between these has an implication of performance. In other words, it can be predicted that firms with a greater level of cooperative relationship-strategic fit will produce greater performance than firms with a lower level of fit.

Hypothesis 3: Cooperative relationship-competitive strategy fit will be greater in firms with greater performance compared with firms with lower performance.

\section{B. Research Model}

This study classified cooperative relationship into the intensity of cooperation from the behavioral viewpoint such as technical cooperation, manpower cooperation, financial cooperation, and sale cooperation, as used in the research by [7], and into the quality of cooperation from the attitude viewpoint such as future orientation and win-win cooperation Thus, both behavioral aspect and attitude aspect of cooperation were taken into account.

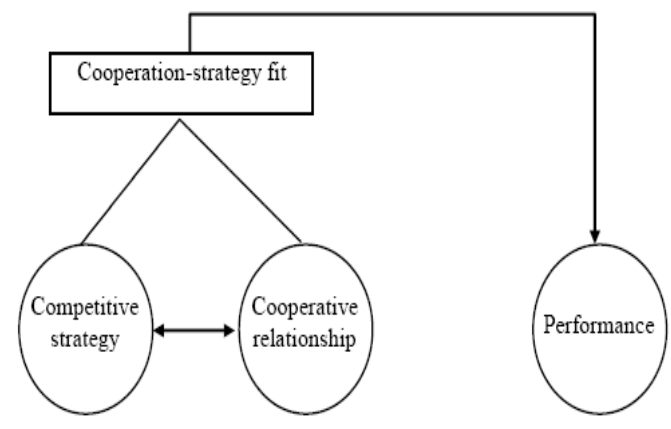

Fig. 1. Research model.

Competitive strategy basically followed the fundamental strategy of [50], and the differentiation strategy was classified into innovation differentiation and marketing differentiation like in research by [6].

Based on such theoretic review, the research model relative to the effect of cooperation relationship and competitive strategy on corporate performance is shown in Fig. 1.

\section{MEASURE}

\section{A. Operational Definition}

Technical cooperation is defined as the supplier's participation in development, sharing of information sharing system, sharing of technology, sharing of material assets, etc. [51]. Items profusely used by Korean SMEs, namely, transfer of technology or level of technical guidance, and the level of provision of market and technology information were measured using 5-point Likert scale's two questions. Financial cooperation was measured in terms of level of support for the procurement of materials and for the purchase of high-price equipment, using 5-point Likert scale's two questions [52]. Sale cooperation was measured in terms of support for logistics and distribution and of publicity of products, using 5-point Likert scale's two questions [53].

The quality of cooperation was measured in terms of win-win cooperation showing cooperation satisfaction and future orientation showing long-term continuity of relationship, using 5-point Likert scale's two questions [54].

For competitive strategy, [50]'s fundamental strategy classification is the most used. However, in some studies, differentiation strategies are classified into technical innovation differentiation and marketing differentiation and used [56]. Thus, this study, based on [50], classifies differentiation strategy into innovation differentiation and marketing differentiation, and measures them. In this study, innovation differentiation was measured in terms of the development of new products through innovative technology and of the development of innovative technology through $R \& D$, using 5-point Likert scale's two questions. Marketing differentiation strategy was measured in terms of advertising and publicity, brand awareness enhancement, attractive design and packaging, using 5-point Lkert scale's three questions. Cost superiority strategy was measured in terms of cost reduction through efficient stock management, and production and operating cost reduction, using 5-point Likert scale's two questions.

To measure corporate performance, this study measured the subjectively-recognized performance targeting corporate CEOs and executives. Questions, used in [20], [55], were revised and used in measuring competitive superiority compared with competitors. Also, in this study, the subjectively recognized performance, based on the middle level, was classified into the high-performance group and the low-performance group. In other words, the high-performance group refers to the group with the subjectively recognized performance above the middle level, and the low-performance group is the group with the subjectively recognized performance below the middle level.

To measure fit, this study used [56]'s fit measurement method. Sampled firms' cooperative relationship-competitive strategy fit was measured to analyze such fit-corporate performance relationship. Like the previous studies' method, fit summary measure values were used to classify samples 
into the high-performance group with greater fit and the low-performance group with the lower fit [16]. All variables underwent standardization process. Such process makes the average 0 and the standard deviation 1 . Also, of hypotheses, only combinations of variables with the confirmation of significant relationship were used in verifying fit. Table I shows the formula of cooperation-strategy fit. The following formula was created based on the logics that variables with a greater fit will show a lower difference between two variables.

TABLE I: FIT SUMMARY MEASURE DERIVATION METHOD

\begin{tabular}{cc}
\hline \hline Types of fit & Method of deriving \\
\hline Cooperation-strategy fit & $F I T_{(C S)}=-\sum_{(s, 1) \in A}\left[\left(Y_{f}\right)-\left(Z_{f}\right)\right]^{2}$ \\
\hline \hline
\end{tabular}

\section{B. Sampling and Data Collection}

For one month and a half from August to mid-September 2012, survey was conducted targeting the executives of Samsung Electronics' primary subcontractors as members of Subcontractors Association by mail and e-mail. The survey aimed to examine influence relationships related to cooperative relationships, and thus the survey targeted only firms within the composition of Samsung Electronics' ecosystem. 160 copies of questionnaire were distributed to 160 subcontractors' executives, and of them, 104 copies were answered. Of them, 90 except 14 were analyzed.

\section{Reliability Analysis}

Table II is results of reliability analysis. To verify the reliability of the measurement tool, of multiple items, those items which hurt reliability were found and excluded from the measurement tool to boost the reliability of the measurement tool. [57], in their study on organizations handling macro-variables, presented the scope of suitable reliability as $0.35 \sim 0.90$. Cronbach's $\alpha$ of questions, used herein, in relation to uncertainty of environment, cooperative relationship, and competitive strategy, were all found to be over 0.5 ; thus, the reliability of the measurement tool was considered no problem.

TABLE II: RESULTS OF ANALYSIS OF RELIABILITY

\begin{tabular}{|c|c|c|c|}
\hline & & & Cronbach's $\alpha$ \\
\hline \multirow{5}{*}{ 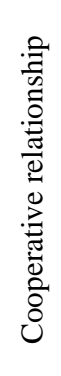 } & \multirow{4}{*}{$\begin{array}{l}\text { Intensity of } \\
\text { cooperation }\end{array}$} & $\begin{array}{c}\text { Technical } \\
\text { cooperation }\end{array}$ & 0.858 \\
\hline & & $\begin{array}{l}\text { Manpower } \\
\text { cooperation }\end{array}$ & 0.528 \\
\hline & & $\begin{array}{c}\text { Financial } \\
\text { cooperation }\end{array}$ & 0.792 \\
\hline & & Sale cooperation & 0.852 \\
\hline & \multicolumn{2}{|l|}{$\begin{array}{l}\text { Quality of } \\
\text { cooperation }\end{array}$} & 0.636 \\
\hline \multirow{3}{*}{\multicolumn{2}{|c|}{ Competitive strategy }} & $\begin{array}{c}\text { Marketing } \\
\text { differentiation }\end{array}$ & 0.852 \\
\hline & & $\begin{array}{c}\text { Innovation } \\
\text { differentiation }\end{array}$ & 0.854 \\
\hline & & Cost superiority & 0.723 \\
\hline
\end{tabular}

\section{Correlation and Regression Analysis}

Table III shows the results of correlation between variables. In the table, Hypothesis 1 concerning the relationship between the intensity of cooperation and competitive strategy was partially adopted. For marketing differentiation strategy, the correlation of technical cooperation, manpower cooperation, and sale cooperation was high at $0.415^{* *}, 0.258^{*}$, and $0.395^{* *}$, respectively. For innovation differentiation strategy, only the correlation of technical cooperation was high at $0.262^{*}$. For cost superiority strategy, only technical cooperation had a correlation $\left(0.218^{*}\right)$.

\begin{tabular}{lllllll}
\multicolumn{6}{c}{ TABLE III: ANALYSIS OF CORREATION BETWEEN VARIABLES } \\
\hline \hline
\end{tabular}

Hypothesis 2 concerning the quality of cooperation and strategic strategy was completely adopted. The correlation between the quality of cooperation, marketing differentiation strategy, innovation differentiation strategy, and cost superiority were high at $.403^{* *}, .432^{*}, .323^{* *}$, respectively.

Meanwhile, variables concerning cooperative relationship had a high correlation, probably creating multicollinearity problems. Thus, without using the average of individual measured items additionally, the factor score based on factor analysis was used for regression analysis. Factor analysis resulted in a total of three factors, and cumulative variance had a high explanation power with over 0.66. Employee education and training were inappropriately combined, and thus they were excluded from the final use of variables. As a result, a factor analysis of two combined items for the intensity of cooperation, and of one item for the quality of cooperation was conducted, and the results were used. The reason for such factor use was because multicollinearity problems due to high correlation between cooperative relationships should be avoided, and because, given that the 
intensity and quality factors of cooperative relationship are somewhat correlational rather than independent, evaluation by factors of cooperative relationship was considered appropriate. To indicate individual factors' orientation, the intensity of cooperation was expressed as technology-led cooperation and finance-led cooperation, and the quality of cooperation was expressed as used above.

To examine the influence relationship between such derived factors and competitive strategy, additional regression analysis was conducted. The results are shown in Table IV and the regression analysis revealed that technology-led cooperation all had a significant effect on competitive strategy, while finance-led cooperation had no significant effect on competitive strategy. Also, the quality of cooperation had a significant effect on all competitive strategies. This showed the influence relationship between cooperative relationship and competitive strategy, as examined above through correlations, revealing that cooperative relationship has significant effects on competitive strategy.

TABLE IV: RESULTS OF REGRESSION ANALYSIS OF COOPERATIVE RELATIONSHIP AND COMPETITIVE STRATEGY

\begin{tabular}{cccc}
\hline \multicolumn{3}{c}{ ReLATIONSHIP AND COMPETITIVE STRATEGY } \\
\hline & & Type of strategy & \\
\hline cooperation & $\begin{array}{c}\text { Marketing } \\
\text { differentiation }\end{array}$ & $\begin{array}{c}\text { Innovation } \\
\text { differentiation }\end{array}$ & $\begin{array}{c}\text { Cost } \\
\text { superiority }\end{array}$ \\
\hline $\begin{array}{c}\text { Technology-led } \\
\text { cooperation }\end{array}$ & $\mathbf{0 . 3 9 3}^{* * *}$ & $\mathbf{0 . 3 3 1}^{* *}$ & $\mathbf{0 . 1 7 8}^{+}$ \\
\hline $\begin{array}{c}\text { Finance-led } \\
\text { cooperation }\end{array}$ & 0.120 & $-0.208^{+}$ & -0.009 \\
\hline $\begin{array}{c}\text { Quality of } \\
\text { cooperation }\end{array}$ & $\mathbf{0 . 2 5 2}^{*}$ & $\mathbf{0 . 3 3 6}^{* *}$ & $\mathbf{0 . 2 8 2}^{* *}$ \\
\hline$R^{2}$ & 0.232 & 0.266 & 0.111 \\
\hline$F$ & $\mathbf{8 . 4 6 4}^{* * * *}$ & $\mathbf{1 0 . 1 4 7}^{* * *}$ & $\mathbf{3 . 5 0 4}^{*}$ \\
\hline \hline
\end{tabular}

\section{E. Verification of Fit}

In this study, to confirm the relationship between fit and performance, as mentioned above, sampled firms were classified into the high-performance group and the lowperformance group, and these groups' fit levels were measured. Toward this end, based on performance data, if the performance was above the middle level, the group was classified into the high-performance group, and if the performance was under the middle level, the group was classified into the low-performance group. Also, of hypotheses, only combinations of variables which proved to have a significant relationship through the correlation analysis and regression analysis performed earlier were used for fit verification. To confirm the fit difference between the two groups, $t$-test was conducted. Table $\mathrm{V}$ shows the results of $t$-test of fit by performance group. $t$-test revealed that there was a significant difference in fit between the high-performance group and the low-performance group. It was found that there was a difference in cooperation- strategy fit between the high-performance group and the low-performance group, and that the high-performance group had a greater fit than the low-performance group. This suggests that a corporation should have a greater cooperative relationship-competitive strategy fit in order to accomplish greater achievements.
TABLE V: RESUlTS OF T-TEST OF BY PERFORMANCE GROUP

\section{Average by group type}

\begin{tabular}{cccc}
\hline Type of fit & $\begin{array}{c}\text { High-performance } \\
\text { group }\end{array}$ & $\begin{array}{c}\text { Low-performance } \\
\text { group }\end{array}$ & t-value \\
\hline $\begin{array}{c}\text { Cooperation- } \\
\text { strategy fit }\end{array}$ & -6.30 & -10.37 & $-1.996^{*}$ \\
\hline \hline${ }^{+} p<0.1,{ }^{*} p<0.05,{ }^{* *} p<0.01,{ }^{* * *} p<0.001$ & \\
\hline
\end{tabular}

\section{CONCLUSION}

This study sought to identify the effect of the fit between cooperative relationship and competitive strategy. Toward this end, Samsung Electronics' subcontractors were surveyed, and the final 90 effective answered copies of questionnaire were analyzed.

This study is outlined as follows: First, in the relationship between cooperative relationship and competitive strategy, in the case of the intensity of cooperation as the behavioral aspect of cooperation, only technology-led cooperation had a positive effect on differentiation strategy and cost superiority strategy. Finance-led cooperation had no significant relationship with competitive strategy, and even a negative effect on innovation differentiation strategy. Thus, in cooperation between large companies and SMEs, technology-led cooperation such as technical cooperation and manpower cooperation are found to be important. Second, the quality of cooperation as attitude aspect of cooperation had a positive effect on all competitive strategies, suggesting that SMEs' pursuit of competitive strategies may greatly differ depending on their cooperative relationship with large companies. This suggests that in the cooperative relationship between large companies and SMEs, long-term-oriented and productive cooperation has important effects on subcontractors' competitive strategy and competitiveness. Third, in order to accomplish greater achievements, it is important for a firm to have cooperation- strategy fit. These findings of research suggest that to secure competitive superiority, a firm should select choose strategies optimal for cooperative relationships. This empirically proved that a firm's cooperation-competitive fit has a positive effect on corporate performance, which was only proved theoretically in previous studies. Also, both attitude and behavioral aspects of cooperation were simultaneously considered, their effects on corporate competitive strategies were empirically analyzed, thus offering the direction for shared growth.

This study has the following limitations and future research direction. First, in relation to performance measurement, due to limitations of measurement, subjective performance measurement results were used as variables. Although such subjective performance measurement results have the advantage of considering individual firms' important performance variables and controlling industrial effects [55] and [58], objective financial performance should be reviewed in order to conduct accurate measurement. Thus, future research needs to examine both subjective and objective performance indices. Second, results based on limited samples cannot be generalized to be applied to diverse industries. Thus, future research should examine a greater number of samples of firms in diverse industries. 


\section{REFERENCES}

[1] J. W. Lee, The Win-Win-Growth, 1st ed., Seoul: Miraeinbooks, 2011.

[2] The Bank of Korea, Financial Statement Analysis for 2010, July 2011.

[3] T. Burns and G. M. Stalker, The Management of Innovation, London: Tavistock, 1961.

[4] P. R. Lawrence and J. W. Lorsch, Organization and Environment, Boston: Harvard University Press, 1967.

[5] J. D. Thompson, Organizations in Action, New York: McGraw-Hill, 1967.

[6] J. W. Lee, D. Miller, S. J. Woo, and J. W. Son, "The Fit between strategy and environment and performance in two technological contexts," Korean Management Review, vol. 23, no. 1, pp. 149-172, 1993.

[7] J. W. Lee and Y. W. Kang, "Impact on the cooperation with large enterprise on technological innovation of SME: an exploratory study," Asia Pacific Journal of Small Business, vol. 28, no. 3, pp. 243-268, 2006.

[8] K. C. Kim, S. W. Kim, G. S. Park, S. T. Park, J. Y. Park, C. S. Song, C. O. Rhee, I. Lim, H. Y. Kang, and J. W. Han, "Building a sound and sustainable business eco-system $=\mathrm{a}$ theoretical framework for collaborative partnerships between large and small to medium size companies," Asia Pacific Journal of Small Business, vol. 28, no. 3, pp. 381-410, 2006

[9] K. T. Lee and C. U. Kim, "Effects of cooperation on corporate performance in small and medium-sized interfirms: A study on the moderating effects of entrepreneurship and environment factor," Journal of Economic Studies, vol. 26, no. 4, pp. 209-232, 2008.

[10] M. S. Rhee, S. B. Park, and I. W. Jun, "Analysis of the relationship among cooperative personnel, management performance and a win-win cooperation of large and small businesses," Korea Logistics Review, vol. 21 , no. 5, pp. 347-371, 2011.

[11] J. H. Lee, "Antecedents and consequences of cooperation -focused on team-based organization," Journal of Economic Studies, vol. 19, no. 1, pp. 157-183, 2001

[12] R. Raubitschek, "Hitting the the jackpot: product proliferation by multiproduct firms under uncertainty," International Journal of Industrial Organazation, vol. 6, pp. 469-488, 1988.

[13] D. C. Hambrick, "High profit strategies in mature capital goods industries: a contingency approach," Academy of Management Journal, vol. 27 , pp. $25-41,1983$.

[14] G. G. Dess and P. S. Davis, "Porter's generic strategies as determinants of strategic group membership and organization performance,' Academy of Management Review, vol. 27, pp. 467-488, 1984.

[15] A. Ginsberg and N. Venkatraman, "Contingency perspective of organizational strategy: a critical review of the empirical research," Academy of Management Journal, vol. 10, no. 3, pp. 421-434, 1985.

[16] A. V. D. Ven and R. Drazin, "The concept of fit in contingency theory," Research in Organizational Behavior, vol. 7, pp. 333-365, 1985.

[17] J. Child, "Organizational structure, environment, and performance: The role of strategic choice," Sociology, vol 6, pp. 2-22, 1972.

[18] R. E. Miles and C. C. Snow, Organizational Strategy, Structure and Process, New York: McGraw-Hill, 1978.

[19] C. Hofer and D. E. Schendel, Strategy Formulation: Analysis Concepts, St. Paul, MN: West Publishing Co.

[20] A. K. Gupta and V. Govindarajan, "Business unit strategy, managerial characteristics at strategy implementation," Academy of Management Journal, vol. 27, pp. 25-41, 1984

[21] G. G. Dess and D. W. Beard, "Dimensions of organizational task environments," Administrative Science Quarterly, vol. 29, no. 1, pp. 52-73, 1984.

[22] D. Miller and P. H. Friesen, "Strategy making and environment: the third link," Strategic Management Journal, vol. 4, pp. 221-235, 1983.

[23] C. C. Snow and L. G. Hrebiniak, "Strategy, distinctive competence and organizational performance," Administrative Science Quarterly, vol. 25, pp. 317-336, 1980.

[24] J. B. Barney, "Firm resource and sustained competitive advantage," Journal of Management, vol. 17, no. 1, pp. 99-120, 1991.

[25] J. T. Mahoney and J. Pandian, "Resource-base view within the convergence of strategic management," Strategic Management Journal, vol. 13 , no. 5, pp. 363-380, 1992.

[26] B. Wernerfelt, "A resource based view of the firm," Strategic Management Journal, vol. 5, pp. 171-180, 1984.

[27] J. Preffer and G. R. Salancik, The External Control of Organizations, New York: Harper \& Row, 1978.

[28] T. K. Das and B. S. Teng, "Partner analysis and alliance performance," Scandinavian Journal of Management, vol. 19, pp. 279-308.

[29] J. Mohr and R. Spekman, "Characteristics of partnership success: partnership attitudes, communication behavior, and conflict resolution techniques," Strategic Management Journal, vol. 15, no. 2, pp. 135-152, 1994.

[30] J. C. Anderson and J. A. Narus, "A model of distributor firm and manufacturer firm working partnership," Journal of Marketing, vol. 54, pp. 42-58, 1990.

[31] K. G. Smith, S. J. Carrol, and S. J. Ashford, "Intra and interorganizational cooperation: toward a research agenda," Academy of Management Journal, vol 38, no. 1, pp. 7-23, 1995.

[32] P. S. Ring and A. H. V. D. Ven, "Structuring cooperative Relationships between organizations," Strategic Management Journal, vol. 13, pp. 483-498, 1994.

[33] S. H. Kim and J. H. Kim, "Success factors of inter-firm collaboration: moderated effects of contextual factors," Daehan Journal of Business, vol. 20, no. 2, pp. 913-937, 2007

[34] M. H. Yun, "Exploring factors affecting relationship quality and strength in local exporters," Asia Marketing Journal, vol. 9, no. 3, pp. 33-73, 2007.

[35] L. L. Bove and L. W. Johnson, "Customer relationships with service personnel: do we measure closeness, quality or strength," Journal of Business Research, vol. 54, pp. 189-197, 2001.

[36] L. A. Crosby, K. R. Evans and D. Cowles, "Relationship quality in service selling: an interpersonal influence perspective," Journal of Marketing, vol. 54, no. 7, pp. 68-81.

[37] M. Granovetter, "The strength of weak ties," American Journal of Sociology, vol. 78, no. 6, pp. 1360-1380, 1973.

[38] J. Sydow and A. Windeler, "Organizing and evaluating inter-firm networks: a structurationist perspective on network processes," Organizational Science, vol. 27, no. 4, pp. 47-75, 1998.

[39] D. W. Sohn, "The role of trust in the creation of economic value in organizations," Journal of Business Research, vol. 17, no. 1, pp. 285-312, 2002

[40] R. M. Kanter, "Collaborative advantage: the art of challenge," Harvard Business Review, July-August, pp. 96-106, 1994.

[41] E. Garbarino and M. S. Johnson, "The different roles of satisfaction, trust and commitment in customer relationships," Journal of Marketing, vol. 63 , no. 2 , pp. 70-87, 1999.

[42] E. Anderson and B. A. Weitz, "Determinants of continuity in conventional industrial channel dyads," Marketing Science, vol. 8, pp. 310-323, 1989.

[43] K. D. Wulf, G. O. Schroder, and D. Iacobucci, "Investments in consumer relationships: a cross-country and cross-industry exploration," Journal of Marketing, vol. 65, no. 4, pp. 33-50, 2001.

[44] T. Saxton, "The effects of partner and relationship characteristics on alliance outcomes," Academy of Management Journal, vol. 40, no. 2, pp. 443-461, 1997.

[45] W. Powell, "Hybrid organizational arrangements: new form of transitional development," California Management Review, vol. 30, no. 1, pp. 67-87, 1987.

[46] P. Bastos, "Inter-firm collaboration and learning: the case of Japanese automobile industry," Asia Pacific Journal of Management, vol. 18, pp. 423-441, 2001

[47] J. Tidd, "Development of novel products through intraorganizational and interorganizational networks: The case of home automation," Journal of Product and Innovation Management, vo. 12, pp. 307-332, 1995.

[48] J. W. Lee, "Small firm's innovation in two technological settings," in Proc. The Korean Society for Innovation Management and Economics, vol. 4, pp. 119-128, 1994.

[49] Y. S. Lee, J. H. Baek, and J. H. Kim, "Effects of collaboration and interorganizational IT usage on the performance of suppliers," Journal of the Korean Production and Operations Management Society, vol. 14, no. 3, pp. 51-74, 2004.

[50] M. E. Porter, Sompetitive Strategy: Techniques for Analyzing Industries and Competitiors, New York: Free Press, 1980.

[51] G. L. Ragatz, R. B. Handfield, and T. V. Scannell, "Success factors for integrating suppliers into new product development," Journal of Product Innovation Management, vol. 14, no. 3, pp. 190-202, 1997.

[52] J. H. Kim and G. H. Jo, Reorganization of Globalization and Subcontract System, Korea Development Institute, 1991.

[53] R. M. Morgan and S. D. Hunt, "The commitment-trust theory of relationship marketing," Journal of Marketing, vol. 58, pp. 135-152, 1994.

[54] D. M. Lambert, A. E. Margaret, and J. T. Gardner, "Building successful logistics partnership," Journal of Business Logistics, vol. 20, no.1, pp. $165-181,1999$

[55] A. K. Gupta, "SBU strategies, corporate-SBU relations, and SBU effectiveness in strategy implementation," Academy of Management Journal, vol. 30, no. 3, pp. 477-500, 1987. 
[56] D. Miller, "External fit versus internal fit," Organizational Science, vol. 3, no. 2, pp. 159-178, 1992.

[57] A. V. de Ven and D. Ferry, Measuring and Assessing Organization, New York: Willey, 1979.

[58] V. Govindarajan and J. Fisher, "Strategy, control-systems and resource sharing: effects on business unit performance," Academy of Management Journal, vol. 33, no. 2, pp. 259-285, 1990.

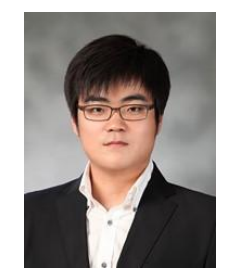

Min-Jae Kim was born in Andong City, South Korea, on June 24, 1985. He earned a master degree at Kyungpook National University in 2013. Since 2011, he has been a researcher at KNU Center for Culture Industry Research. Currently, he is a senior researcher. In 2012, he presented his dissertations in three overseas symposiums. His major research areas include corporate ecosystems, shared growth, and collaboration between firms. In this connection, he conducted case studies on Samsung Electronics, $\mathrm{CJ}$ and KT.

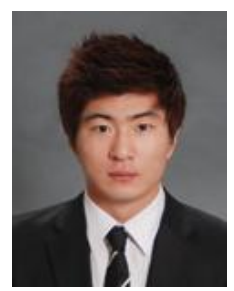

Jeongki Lee was born in Busan, South Korea, on July 29, 1987. He earned a bachelor's degree in business administration at Kyungpook National University in 2012. He is in the master's course in business administration at Kyungpook National University and also he is a researcher at KNU Center for Cultural Industry Research. His major Research areas include Corporate ecosystems, Cooperation between firms, and Creating Shared Value.

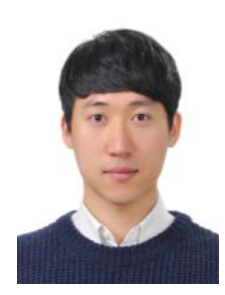

Jun-Young Park was born in Daegu, South Korea, on August 27, 1987. He earned a bachelor's degree in College of Business \& Economics at Yeungnam University in 2012. He is in the master's course at Kyungpook National University and also $\mathrm{He}$ is a junior researcher at KNU Innovation Center. Currently, he has studied the industry of mobile-health. His major research areas include innovation, organizational learning, and leadership. 